\title{
Biology and augmentation of tendon-bone insertion repair
}

Pauline Po-Yee Lui ${ }^{1,2,3^{*}}$, Peng Zhang ${ }^{4}$, Kai-Ming Chan ${ }^{1,2}$, Ling Qin ${ }^{1,4^{*}}$

\begin{abstract}
Surgical reattachment of tendon and bone such as in rotator cuff repair, patellar-patella tendon repair and anterior cruciate ligament $(\mathrm{ACL})$ reconstruction often fails due to the failure of regeneration of the specialized tissue ("enthesis") which connects tendon to bone. Tendon-to-bone healing taking place between inhomogenous tissues is a slow process compared to healing within homogenous tissue, such as tendon to tendon or bone to bone healing. Therefore special attention must be paid to augment tendon to bone insertion (TBI) healing. Apart from surgical fixation, biological and biophysical interventions have been studied aiming at regeneration of TBI healing complex, especially the regeneration of interpositioned fibrocartilage and new bone at the healing junction. This paper described the biology and the factors influencing TBI healing using patella-patellar tendon (PPT) healing and tendon graft to bone tunnel healing in $\mathrm{ACL}$ reconstruction as examples. Recent development in the improvement of TBI healing and directions for future studies were also reviewed and discussed.
\end{abstract}

\section{The Attachment of Tendon to Bone - Tendon- Bone Insertion (TBI)}

The attachment of tendon to bone presents a great challenge in engineering because a soft compliant material (tendon) attaches to a stiff (bone) material [1]. A high level of stress is expected to accumulate at the interface due to the difference in stiffness of the two materials [2]. This problem is solved by the presence of a unique transitional tissue called "enthesis" at the interface which can effectively transfer the stress from tendon to bone and vice versa through its gradual change in structure, composition and mechanical behavior. There are two types of entheses at the tendon to bone insertion (TBI) based on the how the collagen fibers attach to bone [3]. Direct insertions (also called the fibrocartilaginous entheses), such as the insertion of anterior cruciate ligament (ACL), Achilles tendon, patellar tendon, and rotator cuff as well as femoral insertion of medial collateral ligament (MCL), is composed of four zones in order of gradual transition: tendon, uncalcified fibrocartilage, calcified fibrocartilage and bone (Figure 1). The continuous change in tissue composition from tendon to bone is presumed to aid in the efficient transfer of

\footnotetext{
* Correspondence: pauline@ort.cuhk.edu.hk; qin@cuhk.edu.hk 'Department of Orthopaedics and Traumatology, Faculty of Medicine, The Chinese University of Hong Kong, Hong Kong SAR, China Full list of author information is available at the end of the article
}

load between the two materials. Current research also indicates that the mineralized interface region exhibited significantly greater compressive mechanical properties than the non-mineralized region [4]. In direct insertions, tendon/ligament fibers are passed directly into the cortex in a small bone surface area. Superficial fibers are inserted into the periosteum, but deep fibers are attached to bone at right angles or tangentially in the transition. Indirect insertions (also called fibrous entheses), such as the tibial insertion of the MCL and the insertion of the deltoid tendon into the humerus, has no fibrocartilage interface. The tendon/ligament passes obliquely along the bone surface and inserts at an acute angle into the periosterum and is connected by Sharpey's fiber over a broader area of tendon and bone [5,6]. Indirect and direct insertions confer different anchorage strength and interface properties at the tendon-bone interface. The main factors affecting the type of insertion seem to be strain, site, length and angle of insertion. When a ligament runs parallel to the bone, as in the MCL, the insertion is more likely to be indirect, while when the ligament enters the bone quite perpendicularly (as in ACL), the insertion is direct. Indirect insertion may be elevated off the bone without cutting the ligament itself, where direct insertion requires cutting the substance of the ligament to detach it [7].

\section{Biomed Central}




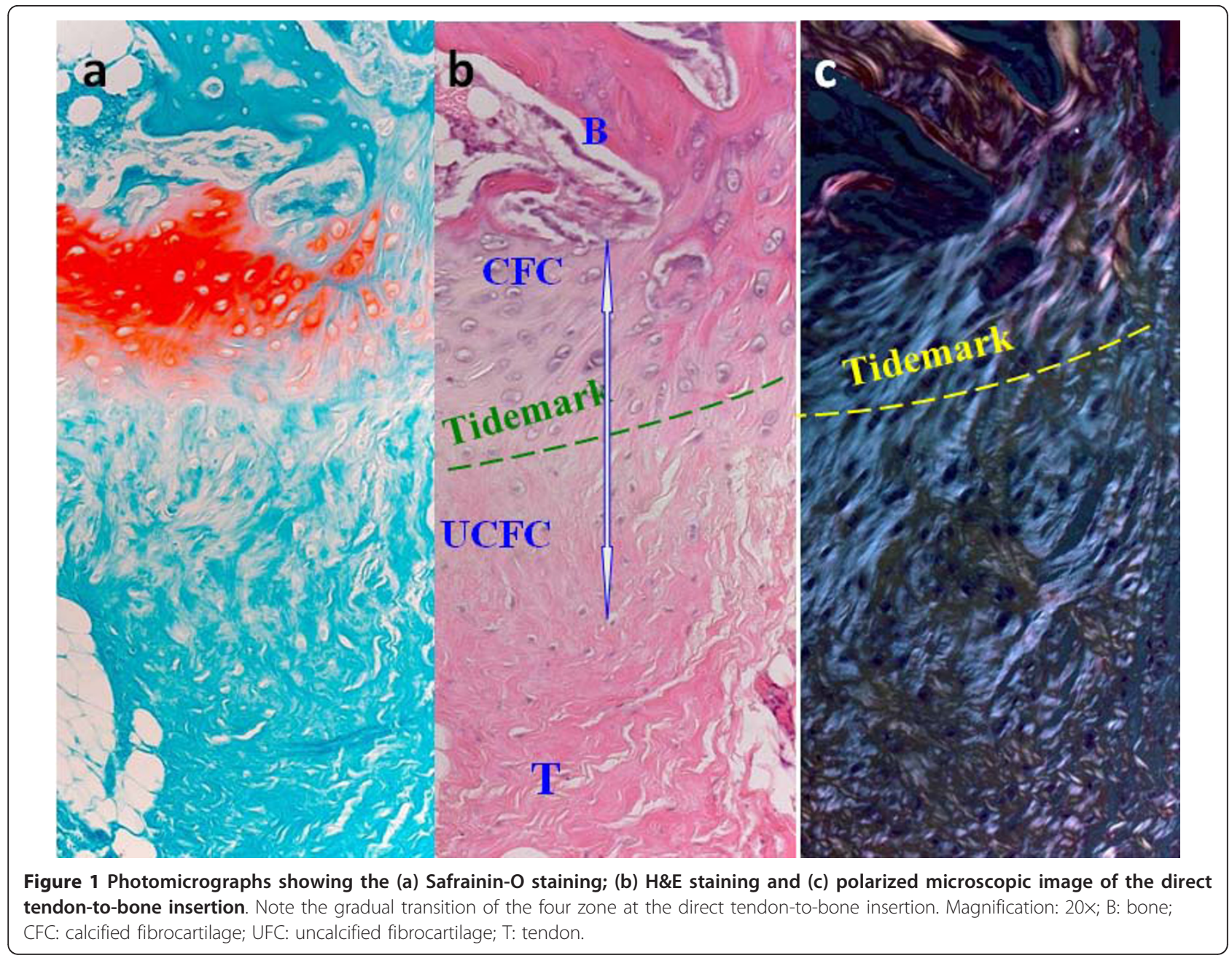

TBI injuries are very common in sports. Surgical reattachment of tendon and bone often fails and presents difficulty for tendon to bone healing due to the lack of regeneration of this specialized structure [8-15]. For example, the failure rates for rotator cuff repair have been reported to range from $20 \%$ to $94 \%$ [16,17]. Similarly, ACL reconstruction, which requires a tendon graft to be put inside a bone tunnel, has failure rate ranged $10 \%-25 \%$, depending on the evaluation criteria used [18]. It is hypothesized that poor vasculature at the fibrocartilage zone in the enthesis may contribute to the poor healing response. However, the issue is more complicated as factors like mechanical loading, extracellular matrix composition and biological factors are likely to interact to affect the healing outcome. Better understanding of its natural healing process as well as factors influencing its healing is essential to the improvement of outcome of TBI healing. This paper therefore aimed to review the biology of healing in preclinical animal models as well as the current biological and biophysical treatment modalities for the augmentation of the regeneration of TBI, using direct tendon to bone repair in patellar-patella tendon (PPT) and tendon graft healing inside a bone tunnel in anterior cruciate ligament (ACL) reconstruction as examples.

\section{Challenges in Different Types of TBI Healing 2.1 ACL reconstruction}

ACL is an important static stabilizer of the knee. Tears or ruptures of ACL are very common painful injuries, especially in sports medicine. Our previous study showed that $38.5 \%$ of male patients who underwent knee arthroscopy following trauma had ACL tears [19]. ACL cannot repair itself when injured. ACL reconstruction is therefore frequently performed in order to restore joint stability and thereby minimize injury to both the chondral surfaces and surrounding tissues. Approximately 95,000 incidences of acute rupture of ACL occur and more than 50,000 knees are reconstructed annually in US [20]. Conventional ACL reconstruction is not a universally successful procedure, with failure rate ranged $10 \%-25 \%$, depending on the 
evaluation criteria used [18]. The clinical challenges associated with ACL reconstruction are graft laxity and inferior mechanical properties compared to those of native insertion; unsatisfactory time and protocol for rehabilitation and donor site morbidity.

As ACL has poor healing capacity, reconstruction of ACL with tendon graft is commonly performed. Autologous bone-patellar tendon bone and hamstring grafts are presently the most commonly used grafts for ACL reconstruction, with the use of hamstring tendon autograft becoming more popular given the morbidity induced by using bone-patella tendon-bone autograft. It is important to note that bone-to-bone healing occurs within the tunnels in the bone-patellar tendon bone graft whereas tendon-to-bone healing happens in hamstring graft without bony ends. With the growing popularity of using the hamstring graft for ACL reconstruction, studies on the biology and treatment options for improvement of tendon graft to bone tunnel healing have become the focus of research in ACL reconstruction.

\subsection{PPT repair}

Trauma, overloading or chronic disorder induced injuries to the human patella-patellar tendon complex are not uncommon, such as in patellar fracture, patellar tendon rupture or separation of the patellar tendon from the patella. If injuries involve the patella, the clinical treatment can be fracture repair, partial or even total patellectomy [21,22]. It is well known that the patella is an important functional component of the extensor mechanism of the knee [23]. Therefore, the perceived role of the patella in knee function has profoundly influenced the preferred treatment of injuries to the PPT complex. Since total patellectomy results in permanent dysfunction of the knee with decreased extensor strength, extensor lag, quadriceps atrophy, and ligamentous instability, every effort should be made to preserve as much of the patella as possible and to understand the healing taking place at two different or imhonogenous tissues between patellar tendon and remaining patella. We also demonstrated the inferiority of PPT healing as compared to healing in patellar fracture (bone to bone repair), with no typical intermitted fibrocartilage zone as seen in normal TBI [24].

\section{Animal models for the study of TBI Healing}

\section{1 $\mathrm{ACL}$ reconstruction}

In order to better understand the biology of tendon graft to bone tunnel healing after ACL reconstruction and to develop strategies for the improvement of outcome, animal models are essential. Rabbit, rat, canine and sheep models have been developed and used for the study of natural tendon graft to bone tunnel healing and treatment outcomes. Compared with other animal models, rabbit and sheep models are more commonly used due to their low cost and large size, respectively. Only a few research groups have used rat model due to its small size and hence the difficulty in performing the surgery. Our group has established both the rabbit and rat models [25-30]. Under general anesthesia, the tendon graft is harvested. The ACL is then excised after medial parapatellar arthrotomy. A tibial tunnel and a femoral tunnel with diameter matching the graft diameter are then created from the footprint of the original ACL to the medial side of the tibia or lateral-anterioral femoral condyle, respectively, with an angle of $55^{\circ}$ to the articular surface. The tendon graft is then inserted and routed through the bone tunnels, fixed on the femoral and tibial tunnel exits with suture tied over the neighboring periosteum at maximum manual tension at $30^{\circ}$ of knee flexion. Soft tissue is then closed in layers (Figure 2). The animals will be allowed to have free cage movement immediately after operation as desired clinically.

\subsection{PPT repair}

Direct tendon to bone healing has been studied in different TBI sites using different animal models, including patella-partellar tendon (PPT), Achilles-calcaneus insertion, and rotator cuff tendon in rats, rabbits, canine and baboons [31-33]. Using a partial patellectomy model in rabbits, we have investigated TBI natural healing extensively in the past years [24,33-35]. The beauty of this model is that the sagital section of PPT provides a unique and internal comparison of healing between tendon-to-bone (patellar tendon to the proximal remaining patella) and tendon-to-cartilage (patellar tendon.to articular cartilage of the proximal patella).

Because of poor healing capacity in TBI and TBI healing is often delayed in both experimental models $[36,37]$ and patients [38], how to accelerate its healing process therefore becomes a focus of our musculoskeletal research, including studies using rotator cuff model in dogs [39] and in rats [40] as well as studies from authors' group where we used partial patellectomy model in both goats [33] and rabbits [41-44]. Apart from testing better fixation protocols, such experimental models provide a useful platform for evaluation of potential biological and biophysical interventions developed for the acceleration and/or enhancement of TBI repair.

\section{Nature Healing Process and Factors Affecting TBI Healing}

\subsection{ACL Reconstruction}

4.1.1 Healing process and factors influencing tendon graft to bone tunnel healing

The tendon graft to bone tunnel site is often seen as the weak link at the early stage of ACL reconstructive 


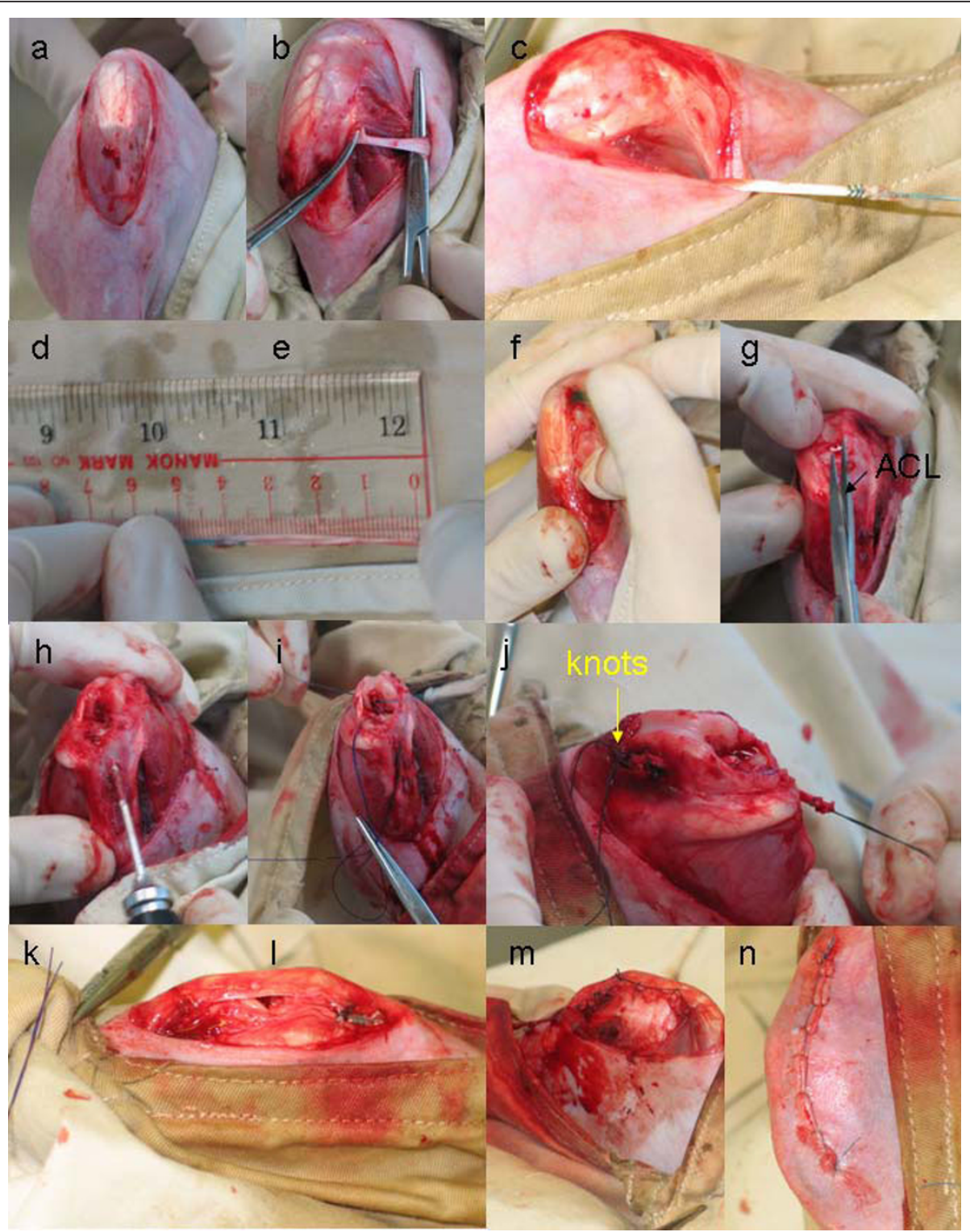

Figure 2 ACL surgical operation procedures. (a) Expose knee joint; (b) Isolation of semitendinous graft; (c) Tide graft with holding suture; (d) Record the length and diameter of the graft; (e) Dislocate the parapatellar and remove the fat pad; (f) Identification and dissection of ACL; (g) Drilling of bone tunnel; (h) Pull the tendon graft into the tunnel; (i) Tide the femoral and tibial ends of graft to periosteum with knots at tension at $30^{\circ}$ knee flexion; (j) Re-locate parapatellar; (k) Parapetaller wound closure; (I) skin wound closure.

surgery. The tendon to bone tunnel complex can achieve only one-tenth of the mechanical strength of native ACL with graft pullout from the bone tunnel at 12 weeks after ACL reconstruction in our rabbit ACL model (Unreported observation). Mechanical and biological factors including graft-tunnel motion, stress deprivation due to graft harvesting and bone drilling, intrusion of synovial fluid after ACL injury, bone necrosis due to trauma, graft necrosis due to avascularity and pressure effect of graft against bone tunnel are the possible factors leading to suboptimal tendon graft to bone tunnel healing in ACL reconstruction. These unfavorable mechanical and biological factors may induce the release of inflammatory cytokines by macrophages, synoviocytes or fibroblasts which may in turns activate osteoclasts for bone resorption and stimulate the production of matrix metalloproteinases (MMPs) for matrix degradation (Figure 3). Understanding the biology of healing is essential to improve the outcome of tendon graft to bone tunnel healing after ACL reconstruction.

Tendon graft to bone tunnel healing can be divided into 4 stages. (1) inflammatory phase; (2) proliferative 


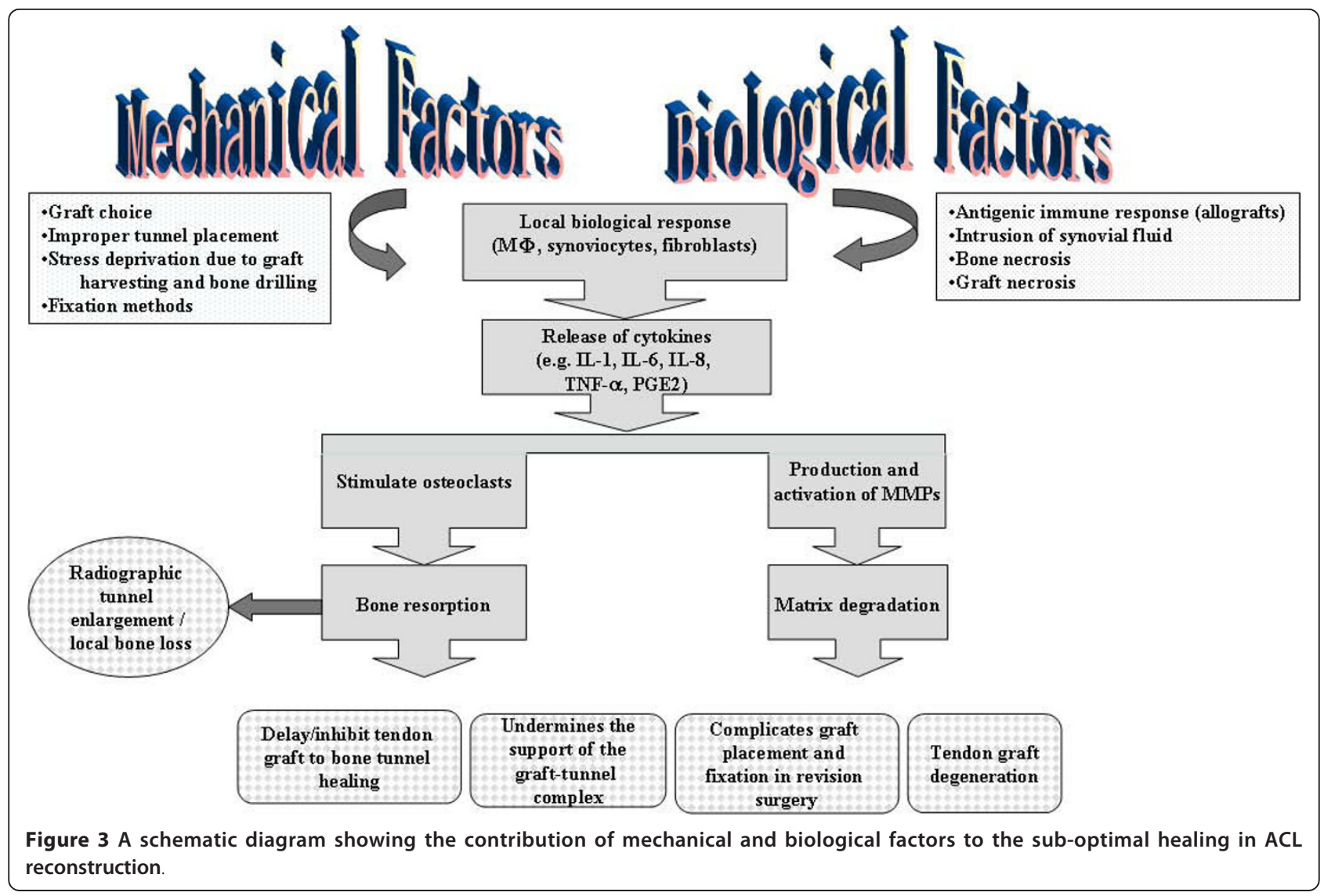

phase; (3) matrix synthesis and (4) matrix remodeling. During the inflammatory phase, there is an infiltration and recruitment of inflammatory cells and marrowderived stem cells to the interface. These cells release cytokines and growth factors including TGF-beta and PDGF. There is an ingrowth of blood vessels and nerves as a result of hypoxia or growth factor stimulation $[45,46]$. The stem cells proliferate and differentiate. During the matrix synthesis phase, MMPs and serine proteases degrade the provisional matrix. The healing cells synthesize and deposit new extracellular matrix with progressive bone ingrowth. At the matrix remodeling phase, the newly-formed bone, interfacial tissue and graft remodel, with establishment of collagen fiber continuity between tendon graft and bone $[28,47,48]$. The cellularity, vascularity and innervation at the interface decrease. The mechanical strength of the tendon-tobone tunnel attachment has been shown to correlate with the amount of osseous ingrowth, mineralization, and maturation of healing tissue [25,49], suggesting that bone formation is critical at the early stage of healing. However, bone formation is not the only factor contributing to healing, graft remodeling and graft to bone tunnel integration also affect tendon to bone tunnel healing in addition to bone mass [30].

\subsubsection{Types of connection between tendon graft and bone tunnel}

Both direct and indirect insertions between tendon graft and bone have been described in the literature. Some studies have demonstrated the formation of a direct type of insertion with cartilaginous interface between tendon graft and bone, resembling the natural transition zone in ACL [50-54]. The follow up time of the previous animal studies, however, was relatively short and hence the observation of chondrocytes at the interface does not necessary imply the persistence of the fibrocartilage zone as in native ACL. Our result has shown that the chondrocytes functioned as intermediate in endonchondral ossification and disappeared with time during healing and the presence of chondrocytes at the tendon-bone interface was commonly associated with Sharpey's fiber formation and hence better healing (Figure 4) [30]. It has been more widely accepted that the insertion type is an indirect one in which Sharpey fibers secure the junction between the tendon graft and bone [55-58]. Chondrocytes in our study were more commonly observed at the juxta-articular segment of both tunnels at week 12 , consistent with the observation of previous studies $[59,60]$. This was probably due to greater contact stress at the joint level which favored 


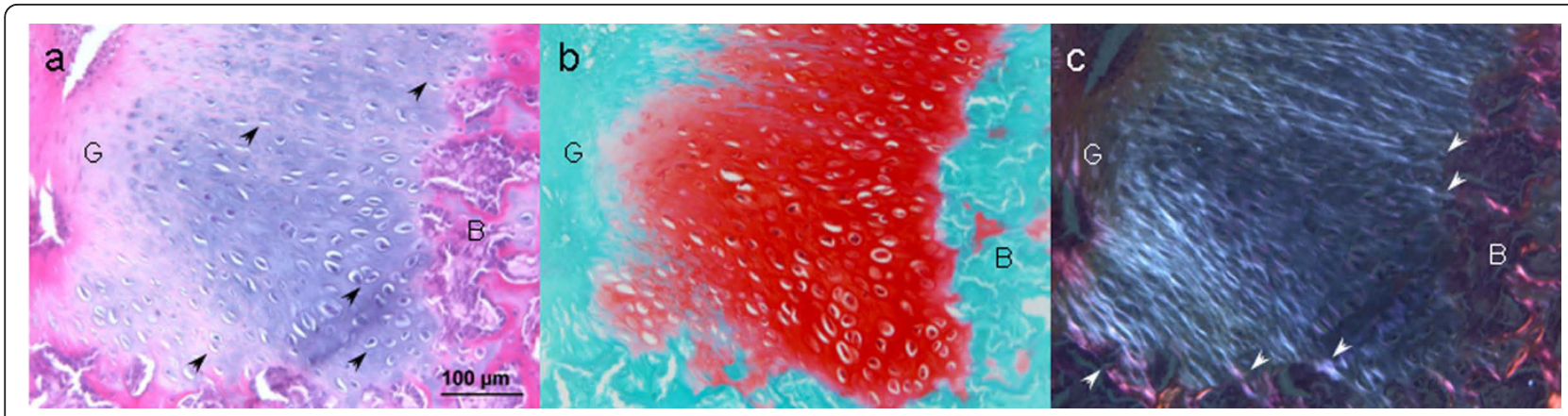

Figure 4 Photographs showing the presence of chondrocytes at the interface between tendon-bone were associated with better Sharpey's fiber formation and better tendon osteointegration. (a) H\&E staining; (b) SO: Safrainin O staining of corresponding H\&E images; (c) Polarized: polarized images of corresponding H\&E images of exit segment of femoral tunnel at week 6 after ACL reconstruction in a rabbit model. Magnification: 200x. B: Bone; dark arrowhead: chondrocytes; G: tendon graft; white arrowhead: Sharpey's fibers.

chondrogenesis while shear load occurred inside the bone tunnel [50]. In our study, complete replacement of tendon graft by bone was observed in some regions along the bone tunnel and we believed that this represented the ideal healing inside the bone tunnel [30].

\subsubsection{Spatial variation in tendon graft to bone tunnel healing}

The healing is not non-uniform at different regions of bone tunnel and at different bone tunnels, with some areas exhibiting better healing than those of the others $[30,47,54,60]$. Our result has shown that healing at the tibal tunnel was inferior compared to that at the femoral tunnel $[28,30]$, resulting in more frequent pull-outs from the tibial tunnel with bone attachment in rabbit models [28]. The exact reason for inferior healing in tibial tunnel was not clear but we speculated it to be related to the local environment where the tunnel was located. The whole femoral tunnel was located in the cancellous bone while only the juxta-articular segment of tibial tunnel was located in the cancellous bone. Previous study reported better healing with chondrocyte-like cells when the graft was inserted into a cancellous bony tunnel compared to a marrow-filled space [61]. We also observed variation in healing response at different tunnel segments [30]. It has been reported that Sharpeylike fibers were not uniformly present at all sites along [62-64] and around the circumference [50,55,59,62] of the bone tunnel. The reasons for the variation is not clear but alteration of the mechanical and biological environment due to bending of the graft at the aperture, graft micromotion (particularly for suspensory fixation), location of graft in cancellous bony versus a marrowfilled space or intrusion of synovial fluid are possible causes [47]. Because of the variation of healing at different regions of bone tunnel, assessment of healing quality in histology can be very subjective and comparison between studies is difficult due to the lack of a uniform standard. We have established a reliable and valid histological scoring system for the assessment of tendon graft to bone tunnel healing in ACL reconstruction [29]. The histological scoring system allows the comparison of outcomes of different interventional studies and facilitates the interpretation of results of biomechanical test in outcome studies.

\subsubsection{Local bone loss after ACL reconstruction}

There is no site in human where a tendon or ligament goes into a bone tunnel. The placement of tendon graft inside an artificially created bone tunnel, while providing a large bone surface for tendon graft to bone tunnel healing, also disrupts the physiological mechanical loading, resulting in regional-dependent stress shielding and subsequent bone loss and thereby also negatively impact healing. We reported that there was regional-dependent loss of surrounding trabeculae after ACL reconstruction, with significantly loss at the medial side of femur tunnel as well as posterior and lateral side of tibial tunnel in a rabbit ACL model [27]. Significant BMD loss with only partial recovery several years after operation (up to 10 years) were also reported in clinical studies [65-72]. This occurred despite accelerated rehabilitation and return to previous levels of activity. However, these were not randomized or controlled clinical studies. Bone loss after tendon insertion site injury and repair has also been reported in other animal studies [73-76]. The excessive local bone loss might delay healing. Tunnel widening might occur (our observation) and resulted in a less stable surface for tendon-bone integration. Inflammatory tendon degeneration might occur due to the degradative enzymes produced during bone resorption. All these, if happens, might prevent the incorporation of collagen fibers into the mineralized tissue, favor fibrous tissue formation and compromise graft-tunnel healing (Figure 3) $[56,74,76]$. Significant bone loss and decreased mechanical properties in the first 21 days after flexor tendon insertion site injury and repair was reported, supporting the relationship between bone loss and 
strength $[73,76]$. A recent study also reported a positive correlation between radiographic tunnel widening and postoperative knee laxity [77]. However, the relationship was not causal. Second, bone tunnel resorption could complicate revision surgery (Figure 3). Moreover, it might undermine the support of graft-tunnel complex and result in graft failure even in the ideal case that the graft-tunnel complex heals perfectly (Figure 3).

\subsection{PPT Repair}

Using the PPT rabbit model, we have described the process of direct TBI healing [32]. The healing process consisted of 4 stages: inflammation, scar tissues formation, osteogenesis and its remodeling, and regeneration of fiborcartilage-like-zone [34,43,44,78,79]. Our results consistently suggested that new bone formation and its size predicted the quality of its postoperative healing quality $[24,78]$. Structurally, we reported that more new bone formed at the patella-patellar tendon healing interface was associated with better regeneration of interpositional fibrocartilage [78]. This is an important bony index for studying the treatment efficacy of potential interventions in vivo or clinically. Whether the findings generated from the PPT healing may also be generalized for radiographic prediction of direct TBI healing quality in regions like Achilles-calcaneus and rotator cuff needs further experimental and clinical investigations.

\section{Recent Development in the Improvement of TBI Healing}

The current treatment and subsequent rehabilitation strategies can be categorized into 3 approaches: surgical or technical, biological and biophysical (Figure 5) [80-83]. A good combination of surgical, biological and biophysical enhancement may improve surgical

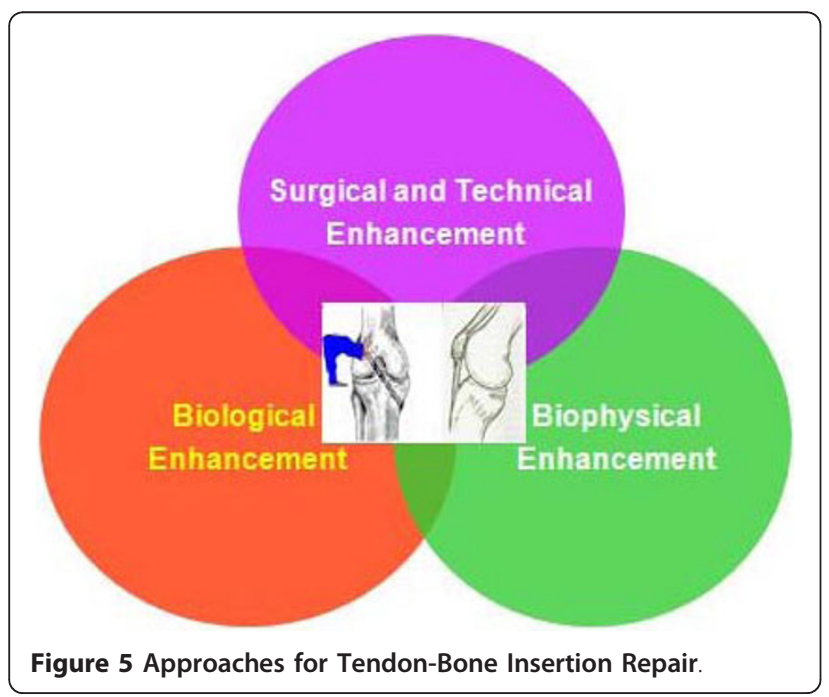

prognosis and enhance postoperative repair. Figure 6 summarized the current treatment methods for TBI repair based on these 3 approaches.

\subsection{ACL reconstruction}

Mechanical strength of tendon graft to bone tunnel attachment has been demonstrated to correlate with the amount of osseous ingrowth, mineralizaton and maturation of healing tissue $[25,49]$. Strategies that can increase bone formation and reduce bone loss are being investigated for the improvement of tendon graft to bone tunnel healing. Various methods have been reported to improve healing of tendon graft inside bone tunnel. They can be classified into growth factors, biomaterial, chemical and biological agents, cell therapy, biophysical modalities and gene therapy.

\subsubsection{Growth factors}

As bone formation is crucial for tendon graft to bone tunnel healing, biological factors such as transforming growth factor-beta1 (TGF-beta1) [84], TGF-beta combined with epithelial growth factor (EGF) [85], recombinant human bone morpohogenetic protein-2 (rhBMP-2) $[74,86]$, bone growth factor [87] and granulocyte colonystimulating factor [88] have been introduced into tendon graft to bone tunnel interface for the augmentation of healing with good histological and biomechanical outcomes.

\subsubsection{Biomaterial}

Since calcium phosphate has chemical composition close to bone, there is a recent interest in its use as an osteoconductive material for bone growth. Injectable and solid forms are available. They are primarily for use as bone void filler for the re-contouring of non-weight bearing craniofacial skeletal defects [89]. We have recently reported the augmentation of screw fixation with injectable hydroxylapatite in the weight-bearing region in osteopenic goat [90]. The material was highly osteoconductive, increased the screw pull-out force and energy required to failure when used in screw augmentation. In view of these favorable properties of calcium phosphate, it can be a good candidate for augmentation of healing and hence fixation of tendon inside bone tunnel. The osteoconductive nature of calcium phosphate might also suppress fibrous tissue formation and promote bone ingrowth into the interfacial gap which increased the fixation of tendon inside bone tunnel. Injectable tri-calcium phosphate (TCP) [91], hydroapatite (HA) [92] and brushite calcium phosphate cement, which composted of dicalcium phosphate dehydrate matrix with beta-TCP granules [26], HA powder in collagen gel [93], magnesium-based bone adhesive [94] and hybridization of calcium phosphate onto the tendon graft [54], have been reported to augment grafted tendon to bone tunnel healing. 


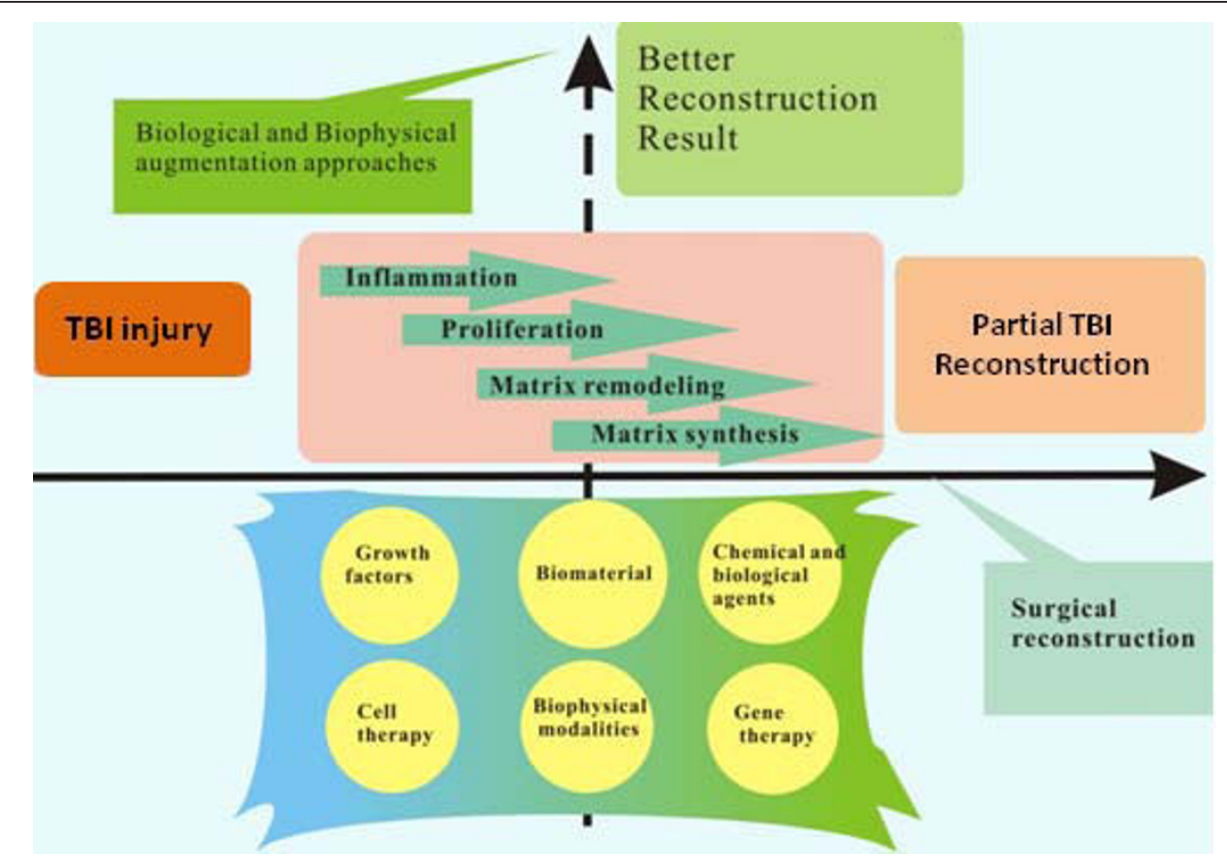

Figure 6 Diagram summarizing TBI injury treatment options currently available.

\subsubsection{Chemical and biological agents}

Chemical and biological agents acting on different biological processes of tendon graft to bone tunnel healing have been studied for the improvement of healing. After ACL injury [95] and ligament reconstruction [96], matrix metalloproteinases (MMPs) increased in the intraarticular environment, which can adversely affect the healing process. As a result, blockage of MMPs with alpha2-macroglobulin, a plasma glycoprotein and an endogeneous inhibitor of MMPs, has been reported to improve healing of tendon graft in a bone tunnel with more matured interfacial tissue and Sharpey's fibers. The ultimate load to failure was also reported to be significantly greater in the treatment group [57].

It has been reported that macrophages accumulated following tendon-to-bone tunnel repair and might contribute to the formation of a scar-tissue interface rather than to the reformation of a normal insertion site. Based on this finding, liposomal clodronate-induced depletion of macrophage following ACL reconstruction was used and reported to significantly improve the morphologic and biomechanical properties at the healing tendonbone tunnel interface [97].

As healing of tendon graft in a bone tunnel depends on bone ingrowth into the interface between tendon and bone, excessive osteoclastic activity may contribute to bone resorption, tunnel widening, and impaired healing. In this regards, inhibition of osteoclastic activity by osteoprotegerin (OPG) was reported to increase bone formation around a tendon graft and improve stiffness at the tendon-bone tunnel complex in ACL reconstruction in a rabbit model, while increased osteoclastic activity due to the application of receptor activator of nuclear factor-kappa B ligand (RANKL) impaired bone ingrowth [98].

During graft remodeling after ACL reconstruction, the tendon graft is infiltrated by inflammatory cells and is subjected to ischemic change. Neovascularization occurs during tendon graft to bone tunnel healing. Therefore, tendon graft to bone tunnel healing is expected to improve with neovascularization and shorten ischemic time. Hyperbaric oxygen ( $\mathrm{HBO})$ treatment, which has been shown to enhance angiogenesis in various tissues [99-101], was reported to increase neovascularization at the tendon-bone tunnel interface, collagen organization in the tendon graft, tendon osteointegration and the maximal pull-out strength in a rabbit ACL model [102].

\subsubsection{Cell therapy}

The application of progenitor cells to promote tendon graft to bone tunnel healing has been reported. The implantation of periosteal autograft [103-106], photoencapsulated rhBMP-2 and periosteal progenitor cells [107], autologous mesenchymal stem cells (MSC) $[53,108,109]$ and synovial MSC [110] and bone marrow aspirates [106] have been reported to accelerate early tendon graft-bone tunnel healing.

\subsubsection{Biophysical modalities}

Shockwave has been used to improve healing at tendonbone tunnel interface in rabbits and the effect of shockwave was found to be time-dependent [111]. The exact 
mechanism of shockwave remains unclear. However, shockwave has been reported to promote bone formation [112], induce neovascularization and improve blood supply at the tendon-bone junction $[113,114]$.

Low-intensity pulsed ultrasound (LIPUS) treatment was also reported to increase the cellular activity at the tendon-bone interface and improved tendon osteo-integration and vascularity in an ovine ACL reconstruction model [115]. Stiffness and peak load of the tendon-bone tunnel complex was also reported to improve compared to the control group after LIPUS treatment [115].

\subsubsection{Gene therapy}

Compared to single application of growth factor protein, delivery of gene to the target tissue has the advantage of sustained and prolonged release of growth factor. In the regards, tendon graft infected with adenovirus-BMP-2 gene has been reported to improve the integration of tendon graft to bone tunnel in an ACL model [116]. Despite the success, safety and regulatory issues need to be solved before introducing a gene transfer modality for treatment in ACL reconstruction clinically.

\subsection{PPT Repair}

\subsubsection{Surgical and technical approaches}

Apart from non-operative approach for TBI repair via limb immobilization, surgical fixation can provide immediate fixation and provide better treatment prognosis. In contrast to fracture fixation which fixes two or more bony fragments, TBI repair needs different sutures and fixation techniques to meet local anatomical and functional demands as biomechanical function of TBI at various skeletal sites varies and there is no standard surgical protocol to follow. Therefore, preclinical and clinical studies are required to make surgical recommendations [117]. For example, Klinger and colleagues [82] compared the timedependent biomechanical properties of the traditional open transosseous suture technique and modified MasonAllen stitches (group 1) versus the double-loaded suture anchors technique and so-called arthroscopic MasonAllen stitches (group 2) in rotator cuff repair in adult female sheep. This in vivo study showed that, postoperatively, the group 2 technique provided superior stability and after healing would gain strength comparable to the group 1 technique.

\subsubsection{Biological agents}

Cytokines play an important role in cell chemotaxis, proliferation, matrix synthesis, and cell differentiation and has been reported to improve TBI healing. The effect of various cytokines and osteoinductive growth factors, such as BMP-2, BMP-7, or rhBMP-12, TGFbeta1, TGF-beta2, TGF-beta3, and fibroblast growth factor, have been tested for TBI healing enhancement. The available data suggested that they were able to improve formation of new bone and fibrocartilage at the healing
TBI site structurally and functionally $[86,118]$. Plateletsrelated products that contain various growth factors have been reported to promote TBI repair $[81,118,119]$. Besides endogenous growth factors, exogenous osteopromotive factors, such as phytoestrogenic herbal compounds may also have promotive effect for TBI healing as some of them have both angiogenic and osteogenic effects [120], suggesting that the osteopromotive formula of Traditional Chinese Medicine (TCM) or herbal medicine should be further explored for their potentials in promoting TBI healing and their associated underlying mechanisms.

\subsubsection{Biomaterial and cell therapy}

A major focus in this area is the development of tissue engineered bone and soft tissue grafts with biomimetic functionality to allow for their translation to the clinical setting. Simple approaches, such as polyglycolic acid sheet has been tested for enhancing TBI repair and regeneration [121]. One of the most significant challenges of this endeavor is promoting the biological fixation of these grafts with each other as well as the implant site. Such fixation requires strategic biomimicy to be incorporated into the scaffold design in order to re-establish the critical structure-function relationship of the native soft tissue to bone interface. The integration of distinct tissue types in TBI necessitates a multiphased or stratified scaffold with distinct yet continuous tissue regions accompanied by a gradient of mechanical properties [122]. Using the partial patellectomy rabbit model, we have demonstrated that cartilage to tendon healing was superior to tendon-to-bone healing at the early healing stage with collagen fibers across the healing interface [34,41]. It is therefore reasonable to believe that the earlier fusion of cartilage to tendon at the insertion might provide earlier stability along the entire PPT healing complex. Indeed, the interposition of autologous articular cartilage improved the transition zone regeneration in TBI healing in our established partial patellectomy model in rabbits [13]. Despite the promising findings in this study, the use of autologous articular cartilage can lead to donor site morbidity. Therefore, we have engineered an allogenic chondrocyte pellet for reconstruction of fibrocartilage zone at TBI $[14,123]$. Despite the improvement in TBI healing with the allogenic chondrocyte pellet, much remains unknown about the basic, translational and clinical application of this technique. For example, what are the signaling mechanisms for transforming the hyaline-like cartilage to fibrocartilage after the transplantation of the allogenic chondrocyte pellet? What are the long-term effects and potential immune responses of allogenic engineered condrocyte pellets as well as the feasibility of generalizing the scientific findings for clinical practice because of high-demands on both good manufacturer practice 
(GMP) and good clinical practice (GCP) even before obtaining FDA or SFDA approval for wide clinical applications?

\subsubsection{Biophyisical modalities}

Due to high costs of biological approaches and the difficulties in their controllable delivery, biophysical modalities have been tested and widely applied in clinical settings, such as mechanical stimulation, electrical stimulation, pulsed electrical magnetic fields (PEMFs), and LIPUS (at 100-200 bursts, 1.5-2 MhZ, $30 \mathrm{~mW} / \mathrm{cm}^{2}$ ) that have been evaluated intensively for their potential for enhancing fracture healing or soft tissue repair; the underlying mechanisms for promoting healing are associated chemical and biological responses due to the mechanical stimulations that are in favor of osteogenesis and angiogenesis [124-127]. Clinically, surgical reattachment of tendon to bone is often followed by a longer period of immobilization. Immobilization-induced problems to musculoskeletal tissues are well known in orthopaedic sports medicine and therefore postoperative rehabilitation programs are highly appreciated. As early motion or direct mechanical stimulation, e.g. tension or cyclic loading via external force onto the healing tissue may impair its healing [127-129], using non-contact 'biomechanical stimulations' would be beneficial for augmentation in early healing phase. LIPUS is such a form of mechanical stimulations, i.e. a noninvasive form of mechanical energy transmitted transcutaneously as high frequency acoustical pressure waves in biologic tissues and thus provides a direct mechanical effect on endochondral ossification, osteoblasts proliferation to produce bone by modulating various biosynthesis processes, including angiogenesis $[35,130,131]$. LIPUS has been documented as a non-invasive mean for accelerating fracture healing, delayed union, non-union, and soft tissue repair process $[43,79,126,130,131]$ as well as promotion of bone mineralization and its remodeling during distraction osteogenesis [132]. The authors of this review paper pioneered in the experimental work for potential clinical indication of LIPUS for accelerating TBI repair and confirmed that LIPUS was generally capable of promoting maturation of inhomogenous tissues, as evidenced with increase in the matrix hardness of the healing tissues at TBI, including new bone, regenerated fibrocartilage and tendon tissues [43], especially with significant augmentation in new bone formation and its remodeling [78]. Similar to soft tissue healing [133], more profound treatment effects were demonstrated in the early healing phase in our series of LIPUS investigation for accelerating TBI repair [42]. Our recent microarray study demonstrated that over 100 genes were related to the underlying molecular mechanism of LIPUS that LIPUS regulated the transient expression of numerous critical genes, especially the cytoskeleton genes in osteoblastic cells [134]. These in vitro results provided further understanding about the role of LIPUS in the regulation of osteoblastic activity potentially involved in osteogensis in TBI repair [134]. A new and interesting finding of this study was up-regulation of genes associated with cell apoptosis, such as BCL2-associated $\times$ protein $(B A X)$, suggesting LIPUS accelerated tissue remodeling by activating apoptotic genes and osteogenesis. Our preclinical findings are appreciated by clinicians and patients. The impact of the research findings of LIPUS for TBI repair can be seen from a personal communication with American LIPUS scientists (Dr. Neil Pounder, Smith \& Nephew, personal communication) "American surgeons prescribe LIPUS for many patients now, even if FDA only allows the application on non-unions and tibial fresh simple fracture. The surgeons prescribe on other sites at their own risk. One prescription is on Achilles tendon junction healing. But the patients need to claim insurance, where your paper is the key evidence for them to claim the insurance". This is a big contribution to the improvement of patient care. However, not all patients may benefit from such findings. Delayed TBI healing was observed in some patients even after treatment with LIPUS during postoperative examinations in our orthopaedic clinics [135]. For the management of delayed healing in patients with TBI surgery, we tested if extracorporeal shockwave (ESW), which is often used for the treatment of delayed union or non-union [127], would be able to promote TBI repair using a recently established delayed TBI healing model in rabbits [37]. Our findings showed that ESW was able to treat delayed TBI injury by triggering osteogenesis, regeneration of fibrocartilage zone, and remodeling in the delayed TBI animal model [136]. Our preclinical data published in the American Journal of Sports Medicine in February issue of 2008 attracted media's great attention and was reported in Reuters Health in New York of USA, with hope of attracting potential clinical applications of ESW in the management of this difficult delayed TBI injury.

Apart from structural restoration of TBI, postoperative functional rehabilitation programs are also essential to achieve full recovery. Exercise program is one of the postoperative rehabilitation programs that help to generate tension to TBI via muscle contraction (concentric force) or passive resistance training (eccentric force). The postoperative programmed FES-induced muscle tension was beneficial for acceleration of TBI repair and was therefore recommended for clinical trials in orthopaedic sports medicine and rehabilitation $[44,127]$. Although the majority of biophysical intervention studies reported positive results, the forms of biophysical stimulation, its dose effect and application timing shall be further carefully determined. 


\section{Research Challenge and Prospect}

Regeneration of the TBI is difficult after injury. This paper described the biology and the factors influencing direct tendon to bone healing using direct attachment of patella-patellar tendon and the tendon graft healing to bone tunnel in ACL reconstruction as examples. Recent work by our group and others in the improvement of tendon to bone healing was also discussed. Despite active research in the understanding of the healing process at the TBI, our understanding is still very limited. Firstly, the origin and maturity of TBI, especially the interpositional fibrocartilage layer have not been clarified. Secondly, the role of different growth factors, mechanical loading and extracellular matrix on natural TBI healing is still not clear. Thirdly, while various biological and biophysical approaches have been demonstrated to be effective for the improvement of TBI healing, the optimal dosage, timing and the underlying mechanisms remain for further investigations. For ACL reconstruction, despite the improvement in tendon graft to bone tunnel healing with different treatment modalities, the mechanical properties of the femur-tendon graft-tibia complex was still inferior to that of the normal ACL and the ultimate failure load can only reach $10-20 \%$ that of intact ligament-bone complex in animal studies although it should be noted that ultimate load is also determined by graft mid-substance remodeling besides the tendon graft to bone tunnel healing. Are we able to jump over this hurdle and achieve a higher ultimate load? Will the combination of different strategies give better results? Can we completely replace the tendon graft inside the bone tunnel by bone and recreate the normal tendon-bone insertion at the intraarticualr tunnel exit in ACL reconstruction? Much research needs to be done to improve our understanding and hence the outcome of TBI healing.

\section{Acknowledgements}

This work was supported by Hong Kong Research Grant Council Earmarked Grant (08/001/ERG) and the Hong Kong Jockey Club Charity Trust.

\section{Author details \\ 'Department of Orthopaedics and Traumatology, Faculty of Medicine, The Chinese University of Hong Kong, Hong Kong SAR, China. ${ }^{2}$ The Hong Kong Jockey Club Sports Medicine and Health Sciences Centre, Faculty of Medicine, The Chinese University of Hong Kong, Hong Kong SAR, China. ${ }^{3}$ Program of Stem Cell and Regeneration, School of Biomedical Science, The Chinese University of Hong Kong, Hong Kong SAR, China. ${ }^{4}$ Translational Medicine Research and Development Center, Institute of Biomedical and Health Engineering, Shenzhen Institutes of Advanced Technology, The Chinese Academy of Science, Shenzhen, Guangdong Province, China.}

\section{Authors' contributions}

PPYL and KMC prepared the review on tendon graft to bone tunnel healing in $\mathrm{ACL}$ reconstruction.

PZ and LQ prepared the review on direct patella-patella tendon repair

\section{Authors' information}

Pauline Po-Yee Lui is currently the assistant professor in the Department of Orthopaedics and Traumatology, The Chinese University of Hong Kong, Hong Kong SAR, China.

Peng Zhang is an Assistant Professor and Director Aassistant of Translational Medicine Research \& Development Center, Institute of Biomedical and Health Engineering, Shenzhen Institutes of Advanced Technology, Chinese Academy of Sciences, in Shenzhen, China.

Ling Qin is the Professor and Director of Musculoskeletal Research

Laboratory, Department of Orthopaedics \& Traumatology, The Chinese University of Hong Kong in Hong Kong, Hong Kong SAR, China and Director of Translational Medicine Research \& Development Center, Institute of Biomedical and Health Engineering, Shenzhen Institutes of Advanced Technology, Chinese Academy of Sciences, in Shenzhen, China. Kai-Ming Chan is the Professor and Chief of Service, Department of Orthopaedics \& Traumatology, The Chinese University of Hong Kong, Hong Kong SAR, China.

\section{Competing interests}

The authors declare that they have no competing interests.

Received: 1 June 2010 Accepted: 21 August 2010

Published: 21 August 2010

\section{References}

1. Jones RM: Mechanics of composite materials Philadelphia: Taylor \& Francis, Inc, 21999.

2. Williams ML: Stress singularities resulting from various boundary conditions in angular corners of plates in extension. $J$ Applied Mechanics 1952, 19:526-528.

3. Benjamin M, Ralphs JR: Fibrocartilage in tendons and ligaments. An adaption to compressive load. J Anat 1998, 193:481-494.

4. Moffat KL, Sun WH, Pena PE, Chahine NO, Doty SB, Ateshian GA, Hung CT, $\mathrm{Lu} \mathrm{HH}$ : Characterization of the structure-function relationship at the ligament-to-bone interface. Proceedings of the National Academy of Sciences of the United States of America 2008, 105:7947-7952.

5. Petersen $W$, Laprell $H$ : Insertion of autologous tendon grafts to the bone: a histological and immunohistochemical study of hamstring and patellar tendon grafts. Knee Surg Sports Traumato. Arthrosc 2000, 8:26-31.

6. Sharpey W, Ellis GV: Elements of anatomy by Jones Quain London: Walton and Moberly, 6 1856, 1.

7. Fadale P, Bluman E, Allen S: Pathophysiology of muscle, tendon and ligament injuries. Sports Medicine Philadelphia: Pennsylvania USASchepsis AA, Busconi BD 2006, 17.

8. Aoki M, Oguma H, Fukushima S, Ishii S, Ohtani S, Murakami G: Fibrous connection to bone after immediate repair of the canine infraspinatus: the most effective ony surface for tendon attachment. J Shoulder Elbow Surg 2001, 10(2):123-128.

9. Fujioka H, Thakur R, Wang GJ, Mizuno K, Balian G, Hurwitz SR: Comparison of surgically attached and non-attached repair of the rat Achilles tendon-bone interface. Cellular organization and type $X$ collagen expression. Connect Tissue Res 1998, 37(3-4):205-218.

10. Liu SH, Panossian V, al-Shaikh R, Tomin E, Shepherd E, Finerman GA, Lane JM: Morphology and matrix composition during early tendon to bone healing. Clin Orthop Relat Res 1997, 339:253-260.

11. St Pierre P, Olson EJ, Elliott JJ, O'Hair KC, McKinney LA, Ryan J: Tendonhealing to cortical bone compared with healing to a cancellous trough. A biomechanical and histological evaluation in goats. J Bone Joint Surg Am 1995, 77:1858-1866.

12. Thomopoulos S, Williams GR, Soslowsky LJ: Tendon to bone healing: differences in biomechanical, structural, and compositional properties due to a range of activity levels. J Biomech Eng 2003, 125:106-113.

13. Wong MWN, Qin L, Lee KM, Leung KS: Articular cartilage increases transition zone regeneration in bone-tendon junction healing. Clin Orthop Relat Res 2009, 467:1092-1100.

14. Wong MWN, Tai KO, Lee KM, Qin L, Leung KS: Bone formation and fibrocartilage regeneration at bone tendon junction with allogeneic cultured chondrocyte pellet interposition. J Bone Min Res 2007, 22:1128-1129. 
15. Rodeo SA, Arnoczky SP, Torzilli PA, Hidaka C, Warren RF: Tendon-healing in a bone tunnel. A biomechanical and histological study in the dog. J Bone Joint Surg Am 1993, 75:1795-1803.

16. Harryman DT II, Mack LA, Wang KY, Jackins SE, Richardson ML, Matsen FA III: Repairs of the rotator cuff. Correlation of functional results with integrity of the cuff. J Bone Joint Surg 1991, 73:982-989.

17. Galatz LM, Ball CM, Teefey SA, Middleton WD, Yamaguchi K: The outcome and repair integrity of completely arthroscopically repaired large and massive rotator cuff tears. J Bone Joint Surg Am 2004, 86A:219-224.

18. Vergis A, Gilquist J: Graft failure in intra-articular anterior cruciate ligament reconstructions: a review of the literature. Arthroscopy 1995, 11:312-321.

19. Chen E, Maffulli N, Chan KM: Knee injuries produced by recreational sports follow a different pattern than causal injuries. Bull Hosp Joint Dis 1998, 57(2):74-79.

20. Miyasaka KC, Daniel DM, Stone ML: The incidence of knee ligament injuries in the general population. Am J Knee Surg 1991, 4(1):3-8.

21. Coleman BD, Khan KM, Kiss ZS: Open and arthroscopic patellar tenotomy for chronic patellar tendinopathy. A retrospective outcome study. Victorian Institute of Sport Tendon Study Group. Am J Sports Med 2000, 28:183-90

22. Schneinberg RR, Bucholz RW: Fractures of the patella. The Knee St. Louis, MosbyScott WN 1994, 1393-403.

23. Sutton FS Jr, Lipke J, Kettelkamp DB: The effect of patellectomy on knee function. J Bone Joint Surg [Am] 1976, 58:537-40.

24. Leung KS, Qin L, Fu LLK, Chan CW: Bone to bone repair is superior to bone to tendon healing in patella-patellar tendon complex - An experimental study in rabbits. J Clin Biomech 2002, 17(8):594-602.

25. Wen CY, Qin L, Lee KM, Chan KM: Peri-graft bone mass and connectivity as predictors for the strength of tendon-to-bone attachment after anterior cruciate ligament reconstruction. Bone 2009, 45(3):545-552.

26. Wen CY, Qin L, Lee KM, Chan KM: The use of brushite calcium phosphate cement for enhancement of bone-tendon integration in an anterior cruciate ligament reconstruction rabbit model. J Biomed Mater Res B Appl Biomater 2009, 89B(2):466-474.

27. Wen CY, Qin L, Lee KM, Wong WN, Chan KM: Influence of bone adaptation of tendon-to-bone healing in bone tunnel after anterior cruciate ligament reconstruction in a rabbit model. J Orthop Res 2009, 27(11):1447-1456.

28. Wen CY, Qin L, Lee KM, Wong MW, Chan KM: Grafted tendon healing in tibial tunnel is inferior to healing in femoral tunnel after anterior cruciate ligament reconstruction: a histomorphometric study in rabbits. Arthroscopy 2010, 26(1):58-66

29. Lui PPY, Ho G, Lee YW, Ho PY, Lo WN, Lo CK: Validation of a histologic scoring system for the examination of quality of tendon graft to bone tunnel healing in ACL reconstruction: TBTH Score (Tendon-Bone Tunnel Healing) score. Anal Quant Cyto Histo

30. Lui PPY, Ho G, Lee YW, Ho PY, Lo WN, Lo CK: Inferior tendon graft to bone tunnel healing at tibia compared to femur after anterior cruciate ligament reconstruction. J Orthop Sci 2010, 15(3):389-401.

31. Sonnabend $D H$, Howlett $C R$, Young AA: Histological evaluation of repair of the rotator cuff in a primate model. J Bone Joint Surg Br 2010, 92(4):586-594.

32. Leung KS, Qin L: Establishment of normal and delayed bone-tendon junction repair models. A Practical Manual for Musculoskeletal Research World ScientificLeung KS, Qin YX, Cheung WH, Qin L 2008, 535-558.

33. Wong NW, Qin L, Lee KM, Tai KO, Chong WS, Leung KS, Chan KM: Healing of bone tendon junction in a bone trough: A goat partial patellectomy model. Clin Orthop Relat Res 2003, 413:291-302.

34. Qin L, Leung KS, Chan CW, Fu LK, Rosier RN: Enlargement of remaining patella after partial patellectomy in rabbits. Med Sci Sports Exer 1999, 31(4):502-506

35. Qin L: Low-Intensity Pulsed Ultrasound (LIPUS): The Effect on Time to Fracture Healing. Orthopedic Trauma Directions 2005, 3(5):22.

36. Shea JE, Hallows RK, Bloebaum RD: Experimental confirmation of the sheep model for studying the role of calcified fibrocartilage in hip fractures and tendon attachments. Anat Rec 2002, 266(3):177-83.

37. Wang L, Qin L, Lu HB, Cheung WH, Hu Y, Chan KM: Establishment of a repeatable delayed bone-tendon healing model in rabbits. $\mathrm{Br} J$ Sports Med 2010, 44(2):114-20.
38. Liu SH, Hang DW, Gentili A, Finerman GA: MRI and morphology of the insertion of the patellar tendon after graft harvesting. J Bone Joint Surg Br 1996, 78(5):823-826.

39. Markel DM: Comparison of healing of allograft/endoprosthetic composites with three types of gluteus medius attachment. J Orthop Res 1995, 13:105-14.

40. Galatz LM, Sandell L, Rothermich SY, Das R, Mastny A, Havlioglu N, Silva MJ, Thomopoulos S: Characteristics of the rat supraspinatus tendon during tendon-to-bone healing after acute injury. J Orthop Res 2006, 24(3):541-550.

41. Lu HB, Qin L, Lee KM, Wong WN, Chan KM, Leung KM: Healing compared between bone to tendon and cartilage to tendon in a partial inferior patellectomy model in rabbits. Clin J Sport Med 2008, 18(1):62-69.

42. Lu HB, Qin L, Cheung WH, Wong WN, Leung KS: Low-Intensity Pulsed Ultrasound Accelerated Bone-Tendon Junction Healing through Regulation of Vascular Endothelial Growth Factor Expression and Cartilage Formation. Ultrasound Med Bio 2008, 34(8):1248-1260.

43. Qin L, Fok PK, Leng Y, Lu HB, Shi SQ, Cheung HW, Leung KS: Low intensity pulsed ultrasound increases the matrix hardness of the healing complex of bone-tendon junction healing - Acoustic microscopic and microindentation study. Clin Biomech 2006, 21(4):387-394.

44. Wang W, Chen HH, Yang XH, Xu G, Chan KM, Qin L: Postoperative programmed muscle tension augmented osteotendinous junction repair. Int J Sports Med 2007, 28:691-696.

45. Haus J, Refior HJ: A study of the synovial and ligamentous structure of the anterior cruciate ligament. Int Orthop 1987, 11(2):117-124.

46. Aune AK, Hukkanen M, Madsen JE, Polak JM, Nordsletten L: Nerve regeneration during patellar tendon autograft remodeling after anterior cruciate ligament reconstruction: an experimental and clinical study. J Orthop Res 1996, 14(2):193-199.

47. Deehan DJ, Cawston TE: The biology of integration of the anterior cruciate ligament. J Bone Joint Surg Br 2005, 87(7):889-895.

48. Carofino B, Fulkerson J: Medial hamstring tendon regeneration following harvest for anterior cruciate ligament reconstruction: fact, myth and clinical implication. Arthroscopy 2005, 21(10):1257-1265.

49. Arnoczky SP, Torzilli PA, Warren RF, Alien AA: Biologic fixation of ligament protheses and augmentation: an evaluation of bone ingrowth in the dog. Am J Sports Med 1988, 16:106-12.

50. Yamakado K, Kitaoka K, Yamada H, Hashiba K, Nakamura R, Tomita K: The influence of mechanical stress on graft healing in a bone tunnel. Arthroscopy 2002, 18(1):82-90.

51. Panni AS, Milano G, Lucania L, Fabbriciani C: Graft healing after anterior cruciate ligament reconstruction in rabbits. Clin Orthop Relat Res 1997, 343:203-212.

52. Weiler A, Peine R, Pashmineh-Azar A, Abel C, Sudkamp NP, Hoffmann RF: Tendon healing in a bone tunnel. Part I: Biomechanical results after biodegradable interference fit fixation in a model of anterior cruciate ligament reconstruction in sheep. Arthroscopy 2002, 18:113-123.

53. Lim JK, Hui J, Li L, Thambyah A, Goh J, Lee EH: Enhancement of tendon graft osteointegration using mesenchymal stem cells in a rabbit model for anterior cruciate ligament reconstruction. Arthroscopy 2004, 20(9):899-910.

54. Mutsuzaki H, Sakane M, Nakajima H, Ito A, Hattori S, Miyanaga Y, Ochiai N, Tanaka J: Calcium-phosphate-hybridized tendon directly promotes regeneration of tendon-bone insertion. J Biomed Mater Res A 2004, 70(2):319-327.

55. Grana WA, Egle DA, Mahnken R, Goodhart CW: An analysis of autograft fixation after anterior cruciate ligament reconstruction in a rabbit model. Am J Sports Med 1994, 22:344-351.

56. Rodeo SA, Amoczky SP, Torzilli PA, Hidaka C, Warren RF: Tendon-healing in a bone tunnel. A biomechanical and histological study in the dog. $J$ Bone Joint Surg Am 1993, 75(12):1795-1803.

57. Demirag B, Sarisozen B, Ozer O, Kaplan T, Ozturk C: Enhancement of tendon-bone healng of anterior cruciate ligament grafts by blockage of matrix metalloproteinases. J Bone Joint Surg Am 2005, 87(11):2401-2410.

58. Blickenstaff KR, Grana WA, Egle D: Analysis of a semitendinosus autograft in a rabbit model. Am J Sports Med 1997, 25(4):554-559.

59. Hunt $P$, Rehm $O$, Weiler $A$ : Soft tissue graft interference fit fixation: observations on graft insertion site healing and tunnel remodeling 2 years after ACL reconstruction in sheep. Knee Surg Sports Traumatol Arthrosc 2006, 114:1245-1251 
60. Rodeo SA, Kawamura S, Kim HJ, Dynybil C, Ying L: Tendon healing in a bone tunnel differs at the tunnel entrance versus the tunnel exit: an effect of graft-tunnel motion? Am J Sports Med 2006, 34(11):1790-1800.

61. Grassman SRM, MCDonald DB, Thornton GM, Shrive NG, Frank CB: Early healing processes of free tendon grafts within bone tunnels is bonespecific: a morphological study in a rabbit model. The Knee 2002, 9:21-26.

62. Goradia VK, Rochat MC, Grana WA, Rohre MD, Prasad HS: Tendon-to-bone healing of a semitendinosus tendon autograft used for $A C L$ reconstruction in a sheep model. Am J Knee Surg 2000, 13:143-151.

63. Tomita F, Yasuda K, Mikami S, Sakai T, Yamazaki S, Tohyama H: Comparisons of intraosseous graft healing between the doubled flexor tendon graft and the bone-patellar tendon-bone graft in anterior cruciate ligament reconstruction. Arthroscopy 2001, 17:461-476

64. Yamazaki S, Yasuda K, Tomita F, Minami A, Tohyama $\mathrm{H}$ : The effect of intraosseous graft length on tendon-bone healing in anterior cruciate ligament reconstruction using flexor tendon. Knee Surg Sports Traumatol Arthrosc 2006, 14(11):1086-1093.

65. Zerahn B, Munk AO, Helweg J, Hovgaard C: Bone mineral density in the proximal tibia and calcaneus before and after arthroscopic reconstruction of the anterior cruciate ligament. Arthroscopy 2006 22(3):265-269.

66. Kannus P, Sievanen $H$, Jarvinen M, Heinonen A, Oja P, Vuori I: A cruciate ligament injury produces considerate, permanent osteoporosis in the affected knee. J Bone Miner Res 1992, 7(12):1429-1434.

67. Leppala J, Kannus P, Natri A, Pasanen M, Sievanen H, Vuori I, Jarvinen M: Effect of anterior cruciate ligament injury of the knee on bone mineral density of the spine and affected lower extremity: a prospective oneyear follow-up study. Calcif Tissue Int 1999, 64:357-363.

68. Rittweger J, Maffulli N, Maganaris CN, Narici MV: Reconstruction of the anterior cruciate ligament with a patella-tendon-bone graft may lead to a permanent loss of bone mineral content due to decreased patellar tendon stiffness. Med Hypotheses 2005, 64(6):1166-1169.

69. Kannus P, Leppala J, Lehto M, Sievanen H, Heinonen A, Jarvinen M: A rotator cuff rupture produces permanent osteoporosis in the affected extremity, but not in those with whom shoulder function has returned to normal. J Bone Miner Res 1995, 10(8):1263-1271.

70. Kartus J, Sterner S, Nilsen R, Nilsson U, Eriksson Bl, Karisson J: Bone mineral assessments in the calcaneus after anterior cruciate ligament injury. An investigation of 92 male patients before and two years after reconstruction or revision surgery. Scand J Med Sci Sports 1998, 8(6):449-455.

71. Sievanen $H$, Kannus $P$, Heinonen A, Oja P, Vuori I: Bone mineral density and muscle strength of lower extremities after long-term strength training, subsequent knee ligament injury and rehabilitation: A unique 2-year follow-up of a 26-year-old female student. Bone 1994, 15:85-90.

72. Ejerhed L, Kartus J, Nilsen R, Nilsson U, Kullenberg R, Karlsson J: The effect of anterior cruciate ligament surgery on bone mineral in the calcaneus: a prospective study with a 2-year follow-up evaluation. Arthroscopy 2004, 20(4):352-359.

73. Silva MJ, Boyer MI, Ditsios K, Burns ME, Harwood FL, Amiel D, Gelberman $\mathrm{RH}$ : The insertion site of the canine flexor digitorum profundus tendon heals slowly following injury and suture repair. $J$ Orthop Res 2002, 20:447-453.

74. Rodeo SA, Suzuki K, Deng XH, Wozney J, Warren RF: Use of recombinant human bone morphogenetic protein-2 to enhance tendon healing in a bone tunnel. Am J Sports Med 1999, 27(4):476-488.

75. Ditsios K, Boyer MI, Kusano N, Gelberman RH, Silva MJ: Bone loss following tendon laceration, repair and passive mobilization. J Orthop Res 2003, 21(6):990-996

76. Galatz LM, Rothermich SY, Zaegel M, Silva MJ, Havlioglu N, Thomopoulos S: Delayed repair of tendon to bone injuries leads to decreased biomechanical properties and bone loss. J Orthop Res 2005, 23(6): 1441-1447.

77. Webster KE, Chiu JJ, Feller JA: Impact of measurement error in the analysis of bone tunnel enlargement after anterior cruciate ligament reconstruction. Am. J Sports Med 2005, 33(11):1680-1687.

78. Lu HB, Qin L, Fok PK, Cheung WH, Lee KM, Guo X, Wong WN, Leung KS: Low Intensity Pulsed Ultrasound Accelerates Bone-Tendon-Junction Healing- A Partial Patellectomy Model in Rabbits. J Am Sports Med 2006, 34(8):1287-1296.
79. Qin L, Lu HB, Fok PK, Cheung WC, Zheng YP, Lee KM, Leung KS: Low intensity pulsed ultrasound accelerates osteogenesis at bone-tendon junction healing junction. Ultrasound Med Biol 2006, 32(12):1905-1911.

80. Gulotta LV, Rodeo SA: Growth factors for rotator cuff repair. Clin Sports Med 2009, 28(1):13-23.

81. Kovacevic D, Rodeo SA: Biological augmentation of rotator cuff tendon repair. Clin Orthop Relat Res 2008, 466(3):622-633.

82. Klinger HM, Steckel H, Spahn G, Buchhorn GH, Baums MH: Biomechanical comparison of double-loaded suture anchors using arthroscopic MasonAllen stitches versus traditional transosseous suture technique and modified Mason-Allen stitches for rotator cuff repair. Clin Biomech (Bristol, Avon) 2007, 22(1):106-111.

83. Benjamin M, Toumi H, Ralphs JR, Bydder G, Best TM, Milz S: Where tendons and ligaments meet bone: attachment sites ('entheses') in relation to exercise and/or mechanical load. J Anat 2006, 208(4):471-490.

84. Yamazaki S, Yasuda K, Tomita F, Tohyama H, Minami A: The effect of transforming growth factor-beta 1 on intraosseous healing of flexor tendon allograft replacement of anterior cruciate ligament in dogs. Arthroscopy 2005, 21(9):1034-1041.

85. Yasuda K, Tomita F, Yamazaki S, Minami A, Tohyama H: The effect of growth factors on biomechanical properties of the bone-patellar tendon-bone graft after anterior cruciate ligament reconstruction: a canine model study. Am J Sports Med 2004, 32(4):870-880.

86. Hashimoto Y, Yoshida G, Toyoda H, Takaoka K: Generation of tendon-tobone interface "enthesis" with use of recombinant BMP-2 in a rabbit model. J Orthop Res 2007, 25(11):1415-1424.

87. Anderson $\mathrm{K}$, Seneviratne AM, Izawa K, Atkinson BL, Potter HG, Rodeo SA: Augmentation of tendon healing in an intraarticular bone tunnel with use of a bone growth factor. Am J Sports Med 2001, 29(6):689-698.

88. Sasaki K, Kuroda R, Ishida K, Kubo S, Matsumoto T, Mifune Y, Kinoshita K Tei K, Akisue T, Tabata Y, Kurosaka M: Enhancement of tendon-bone osteointegration of anterior cruciate ligament graft using granulocyte colony-stimulating factor. Am J Sports Med 2008, 36:1519-1527.

89. Reddi SP, Stevens MR, Kline SN, Villanueva P: Hydroxyapatite cement in craniofacial trauma surgery: indications and early experience. $J$ Craniomaxillofac Trauma 1999, 5(1):7-12.

90. Leung KS, Siu WS, Li SF, Qin L, Cheung WH, Tam KF, Lui PPY: An in vitro optimized injectable calcium phosphate cement for augmenting screw fixation in osteopenic goats. J Biomed Mater Res B Appl Biomater 2006, 78(1):153-160.

91. Huangfu $X$, Zhao J: Tendon-bone healing enhancement using injectable tricalcium phosphate in a dog anterior cruciate ligament reconstruction model. Arthroscopy 2007, 23(5):455-462.

92. Tien YC, Chih TT, Lin JHC, Ju CP, Lin SD: Augmentation of tendon-bone healing by the use of calcium-phosphate cement. J Bone Joint Surg [Br] 2004, 86B:1072-1076.

93. Ishikawa $H$, Koshino $T$, Takeuchi $R$, Saito $T$ : Effects of collagen gel mixed with hydroxyapatite powder on interface between newly formed bone and grafted Achilles tendon in rabbit femoral bone tunnel. Biomaterials 2001, 22(12):1689-1694.

94. Gulotta LV, Kovacevic D, Ying L, Ehteshami JR, Montgomery S, Rodeo SA: Augmentation of tendon-to-bone healing with a magnesium-based bone adhesive. Am J Sports Med 2008, 36:1290-1297.

95. Amiel D, Ishizue KK, Harwood FL, Kitabayashi L, Akeson WH: Injury of the anterior cruciate ligament: the role of collagenase in ligament degeneration. J Orthop Res 1989, 7:486-493.

96. Roseti L, Buda R, cavallo C, Desando G, Facchini A, Grigolo B: Ligament repair: a molecular and immunohistological characterization. J Biomed Mater Res A 2008, 84(1):117-127.

97. Hays PL, Kawamura S, Deng XH, Dagher E, Mithoefer K, Ying L, Rodeo SA: The role of macrophages in early healing of a tendon graft in a bone tunnel. J Bone Joint Surg Am 2008, 90(3):565-579.

98. Rodeo SA, Kawamura S, Ma CB, Deng XH, Sussmann PS, Hays P, Ying L: The effect of osteoclastic activity on tendon-to-bone healing: an experimental study in rabbits. J Bone Joint Surg Am 2007, 89(10):2250-2259.

99. Kindwall EP, Gottieb LJ, Larson DL: Hyperbaric oxygen therapy in plastic surgery: a review article. Plast Reconstr Surg 1991, 88:898-908.

100. Uhl E, Sirsjo A, Haapaniemi T, Nilsson G, Nylander G: Hyperbaric oxygen improve wound healing in normal and ischemic skin tissue. Plast Reconstr Surg 1994, 93:835-841. 
101. Yablon IG, Cruess RL: The effect of hyperbaric oxygen of fracture healing in rats. J Trauma 1968, 8:186-192.

102. Yeh WL, Lin SS, Yuan LJ, Lee KF, Lee MY, Ueng SW: Effects of hyperbaric oxygen treatment on tendon graft and tendon-bone integration in bone tunnel: biochemical and histological analysis in rabbits. J Orthop Res 2007, 25:636-645.

103. Ohtera K, Yamada Y, Aoki M, Sasaki T, Yamakoshi K: Effects of periosteum wrapped around tendon in a bone tunnel: A biomechanical and histological study in rabbits. Crit Rev Biomed Eng 2000, 28(1-2):115-118.

104. Youn I, Jones DG, Andrews PJ, Cook MP, Suh JK: Periosteal augmentation of a tendon graft improves tendon healing in the bone tunnel. Clin Orthop Relat Res 2004, 419:223-231.

105. Chen CH, Chen LH, Chen WJ, Shih CH, Yang CY, Liu SJ, Lin PY: Periosteumenveloping of the tendon to enhance tendon-bone healing in the bone tunnel - Histologic studies in three experimental rabbit models. J Orthop Surg Taiwan 2003, 20:21-29.

106. Karaoglu S, Celik C, Korkusuz P: The effects of bone marrow or periosteum on tendon-to-bone tunnel healing in a rabbit model. Knee Surg Sports Traumatol Arthrosc 2009, 17:170-178.

107. Chen CH, Liu HW, Tsai CL, Yu CM, Lin IH, Hsiue GH: Photoencapsulation of bone morphogenetic protein-2 and periosteal progenitor cells improve tendon graft healing in a bone tunnel. Am J Sports Med 2008, 36(3):461-473.

108. Ge Z, Goh JC, Lee EH: The effects of bone marrow-derived mesenchymal stem cells and fascia wrap application to anterior cruciate ligament tissue engineering. Cell Transplant 2005, 14(10):763-773.

109. Soon MY, Hui JH, Goh JC, Lee EH: An analysis of soft tissue allograft anterior cruciate ligament reconstruction in a rabbit model: a short-term study of the use of mesenchymal stem cells to enhance tendon osteointegration. Am J Sports Med 2007, 35:962-971.

110. Ju YJ, Muneta T, Yoshimura H, Koga H, Sekiya I: Synovial mesenchymal stem cells accelerate early remodeling of tendon-bone healing. Cell Tissue Reg 2008, 332:469-478.

111. Wang CJ, Wang FS, Yang KD, Weng LH, Sun YC, Yang YJ: The effect of shock wave treatment at the tendon-bone interface - a histomorphological and biomechanical study in rabbits. J Orthop Res 2005, 23(2):274-280.

112. Wang CJ, Yang KD, Wang FS, Hsu CC, Chen HH: Shock wave treatment shows dose-dependent enhancement of bone mass and bone strength after fracture of the femur. Bone 2004, 34:225-230.

113. Wang $\mathrm{CJ}$, Huang SY, Pain CH: Shock wave enhanced neovascularization at the bone-tendon junction. A study in a dog model. Am J Foot Ankle 2002, 41:16-22.

114. Wang CJ, Yang Kuender, Wang FS, Huang CC, Yang LJ: Shock wave induces neovascularization at the tendon-bone junction. A study in rabbits. J Orthop Res 2003, 21:984-989.

115. Walsh WR, Stephens P, Vizesi F, Bruce W, Huckle J, Yu Y: Effects of lowintensity pulsed ultrasound on tendon-bone healing in an intra-articular sheep knee model. Arthroscopy 2007, 23:197-204.

116. Martinek V, Latterman C, Usas A, Abramowitch S, Woo SLY, Fu FH, Huard J: Enhancement of tendon-bone integration of anterior cruciate ligament grafts with bone morphogenetic protein-2 gene transfer: A histological and biomechanical study. J Bone Joint Surg Am 2002, 84:1123-1131.

117. Beaudreuil J, Dhénain M, Coudane H, Mlika-Cabanne N: Clinical practice guidelines for the surgical management of rotator cuff tears in adults. Orthop Traumatol Surg Res 2010, 96(2):175-179

118. Rodeo SA: Biologic augmentation of rotator cuff tendon repair. J Shoulder Elbow Surg 2007, 16(5 Suppl):S191-197.

119. Seeherman HJ, Archambault JM, Rodeo SA, Turner AS, Zekas L, D'Augusta D, Li XJ, Smith E, Wozney JM: rhBMP-12 accelerates healing of rotator cuff repairs in a sheep model. J Bone Joint Surg Am 2008, 90(10):2206-2219.

120. Zhang G, Qin L, Sheng H, Wang XL, Wang YX, Yeung DK, Griffith JF, Yao XS, Xie XH, Li ZR, Lee KM, Leung KS: A novel semisynthesized small molecule icaritin reduces incidence of steroid-associated osteonecrosis with inhibition of both thrombosis and lipid-deposition in a dose-dependent manner. Bone 2009, 44(2):345-356.

121. Yokoya S, Mochizuki Y, Nagata Y, Deie M, Ochi M: Tendon-bone insertion repair and regeneration using polyglycolic acid sheet in the rabbit rotator cuff injury model. Am J Sports Med 2008, 36(7):1298-1309.
122. Lu HH, Subramony SD, Boushell MK, Zhang X: Tissue Engineering Strategies for the Regeneration of Orthopedic Interfaces. Ann Biomed Eng 2010, 38(6):2142-2154.

123. Wong MW, Qin L, Tai JK, Lee SK, Leung KS, Chan KM: Engineered allogeneic chondrocyte pellet for reconstruction of fibrocartilage zone at bone-tendon junction - A preliminary histological observation. J Biomed Materials Res 2004, 70B(2):362-367.

124. Einhorn TA, Lane JM, eds: Fracture Healing Enhancement. Clin Orthop Rel Res 1998, 355S.

125. Aaron RK, Ciombor DM, Simon BJ: Treatment of nonunionswith electric and electromagnetic fields. Clin Orthop Relat Res 2004, , 419: 21-29.

126. Malizos KN, Hantes ME, Protopappas V: Low-intensity pulsed ultrasound for bone healing: an overview. Injury 2006, 37(Suppl 1):S56-62.

127. Chao EY, Inoue N, Koo TK, Kim YH: Biomechanical considerations of fracture treatment and bone quality maintenance in elderly patients and patients with osteoporosis. Clin Orthop Relat Res 2004, 425: 12-25.

128. Gimbel JA, Van Kleunen JP, Lake SP, Williams GR, Soslowsky LJ: The role of repair tension on tendon to bone healing in an animal model of chronic rotator cuff tears. J Biomech 2007, 40(3):561-568.

129. Buckwalter JA: Effects of early motion on healing of musculoskeletal tissues. Hand Clin 1996, 12:13-24

130. Einhorn TA: Enhancement of fracture healing. J Bone Joint Surg [Am] 1995, 77:940-56.

131. Klassen JF, Trousdale RT: Treatment of delayed and nonunion of the patella. J Orthop Trauma 1997, 11:188-94.

132. Chan CW, Qin L, Lee KM, Zhang M, Cheng JCY, Leung KS: Low intensity pulsed ultrasound accelerated bone remodelling during consolidation stage of distraction osteogenesis. J Orthop Res 2006, 24(2):263-270.

133. Fu SC, Shum WT, Hung LK, Wong WN, Qin L, Chan KM: Only early application of low intensity pulsed ultrasound (LIPUS) benefited tendon healing. Am J Sports Med 2008, 36(9):1742-1749.

134. Lu H, Qin L, Lee KM, Cheung WH, Chan KM, Leung KS: Identification of genes responsive to low intensity pulsed ultrasound stimulations. Biochem Biophys Res Commun 2009, 16;378(3):569-573.

135. Hung LK, Lee SY, Leung KS, Chan KM, Nicoll LA: Partial patellectomy for patellar fracture: tension band wiring and early mobilization. $J$ Orthop Trauma 1993, 7:252-60.

136. Qin L, Wang L, Wong MW, Wen C, Wang G, Zhang G, Chan KM, Cheung WH, Leung KS: Osteogenesis induced by extracorporea shockwave in treatment of delayed osteotendinous junction healing. $J$ Orthop Res 2010, 28(1):70-76.

doi:10.1186/1749-799X-5-59

Cite this article as: Lui et al:: Biology and augmentation of tendon-bone insertion repair. Journal of Orthopaedic Surgery and Research 2010 5:59.

\section{Submit your next manuscript to BioMed Central and take full advantage of:}

- Convenient online submission

- Thorough peer review

- No space constraints or color figure charges

- Immediate publication on acceptance

- Inclusion in PubMed, CAS, Scopus and Google Scholar

- Research which is freely available for redistribution 